\title{
Blindness and light
}

$\mathrm{T}$ he exploration of blindness through photography is fraught with irony. The very word photography means to write with light. Yet blindness is a natural topic for the social documentary photographer, in that it raises profound questions of ethics, human dignity and social engagement.

Marco Antonio Cruz, a respected photojournalist from Mexico City, has explored these questions in Oscuridad Habitada (Darkness Inhabited), 112 black-and-white photographs that reveal the day-to-day world of blind and visually impaired people in a manner that resonates with respect for human dignity. It's a familiar theme for Cruz, who is photo editor of Proceso, a respected weekly newsmagazine and author of 2 books, Cafetaleros (Coffee Workers) (Imagenlatina, 1996) and Contra la Pared (Against the Wall) (Grupo Desea, 1993). Now Cruz has dedicated 17 years to documenting various forms of blindness, be it congenital, acquired through illness or, as he says bluntly, "acquired through poverty." A book is under way.

Nine of Cruz's photographs were recognized in Canada on May 26 when, in competition with 3 other photographers, he garnered the most public votes to win the prestigious $\$ 50000$ Grange Prize. Sponsored by the Art Gallery of Ontario and Aeroplan, the prize recognizes the "best in Canadian and international contemporary photography."

Although Cruz photographed in 12 of Mexico's states, he was most affected by his experience in the southern state of Chiapas, where he discovered many cases of trachoma, especially among the Aboriginal peoples living in extreme poverty in the highlands with little or no access to medical care and inadequate sanitation facilities. Cruz explains that people who become blind in this part of his country are "condemned to live confined inside their

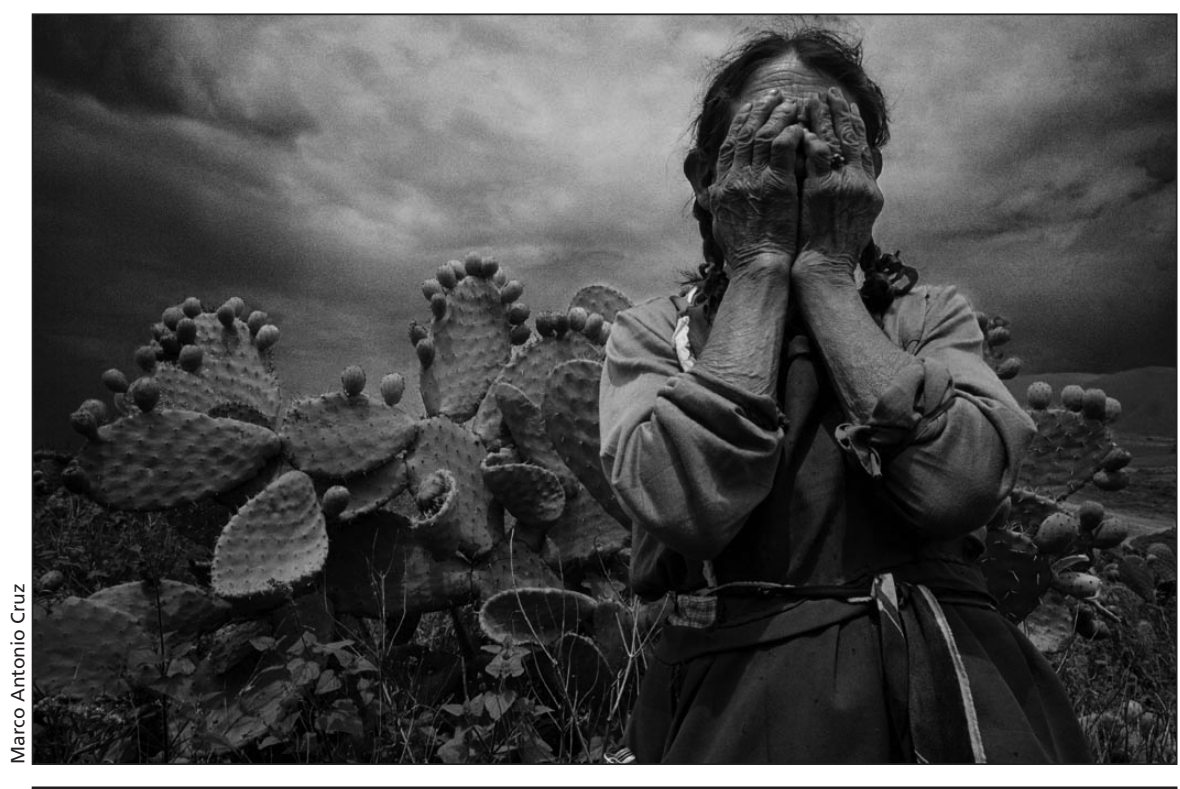

Andrea Islas Garcia was a subsistence farmer (campesina) who became blind as a result of cataracts. She died in 1998 from a cancer that was not treated.

houses, and nothing is known of them, or their existence ... until death."

Cruz has also documented cases of onchocerciasis (river blindness) among coffee workers in northern Chiapas near the Guatemalan border, who frequently work and live near fast-flowing rivers and streams that are the main habitat of the vector insect. At the time of his photographic forays to this part of Chiapas in the late 1990s, Cruz says 70000 people were infected. He bore witness to its devastating effects on individuals who could no longer work, whose family lives were disrupted, and who became dependent on the already meager resources of their family and community.

Cruz also documented the elderly suffering with cataracts. While treatment clinics, staffed by volunteer physicians, are set up in various locales, there simply aren't enough resources. Cruz recalls the time when almost 1500 people showed up at a clinic, but supplies were only sufficient to treat about 120 .
His experiences have made him indignant, but his photographs do more than denounce social conditions that perpetuate cycles of poverty for blind people. He has eloquently photographed the more "intimate aspects of life of blind people, their joys, their emotions, their hopes."

Cruz says, "It's true, of course, that blind people cannot see my photographs. But it is my hope that the photographs will provoke people into being more aware and change conditions in which blind people are condemned to live. I am talking about health, housing and education. I want to make people reflect on social conditions."

One of the photographer's first contacts with blind people was through a chance encounter with a man in San Bartolo Coyotepec, Oaxaca, who was both blind and severely physically disabled. Cruz's photograph shows a man lying in bed, flat on his back, his eyes and forehead covered by a large piece of white gauze, with a radio beside him. His body is very relaxed, except for his hands and 
fingers, which are manipulating letters of the alphabet on a specially designed board, which he he uses for writing. The tension on his hands and contorted fingers is such that all the veins are outlined dramatically, as if steep ridges in a micro landscape. The photograph brings us into his world: paralyzed, save the movement in his fingers. He has been forced by his condition to lie in bed for 20 years and, other than his caregivers, his sole connection to the outside world is his radio.

Cruz was profoundly moved by meeting this man, who instead of giving up, found a way of fighting back: he became a philosopher. "He dedicated his life to thinking, and so he overcame his situation, and it was a marvellous thing to see. A project like this is a constant education about life, about the human condition."

Hands are very important throughout Cruz's work, not surprisingly since they take over some of the functions of sight. In one picture, an elderly woman stands alone in front of a large plant of prickly pears. The sky is ominously dark. The feeling of starkness is accentuated by the mantle of thorns in the leaves of the cactus. The plant is untouchable. Is the

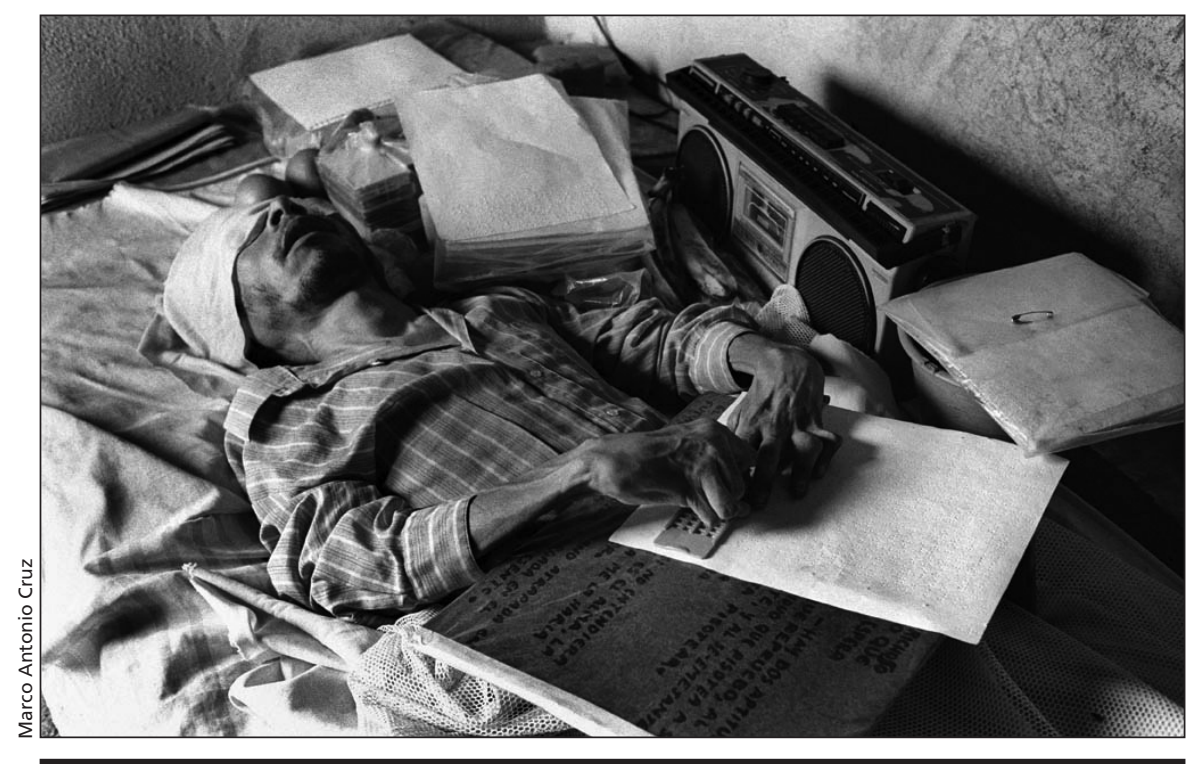

In 1970, at the age of 16, Porfirio Moreno Martinez developed juvenile rheumatoid arthritis and uveitis. After undergoing various treatments, including an unsuccessful operation, Martinez returned to his village, "took hold of the reins of his life" and became a philosopher. This photograph was taken on Mar. 14, 1998. woman also untouchable? Perhaps she bears a burden of infectious disease and ensuing stigma? She is facing the camera, but hides her face with her hands. In a momentary twist of irony, we are prevented from seeing her face, in the same way that she is prevented from seeing "our" face because of her blindness. This is how she holds onto her dignity: her gnarled hands become her face.

In another picture, a young boy is walking in a swimming pool, and we see his tiny hand pulled gently under the water by the much larger hand of an adult. The boy has just surfaced for air but is still holding his breath, his lips shut tightly, and his cheeks bulging. His eyes are fully open, yet we can plainly see that they are sightless. But he smiles with the same innocent pleasure of countless boys when they play with water. We smile back, for we feel a sense of solidarity. We are seeing blindness in new ways, more importantly, the humanity of people who are blind. Such is the power of Cruz's poignant work, which he hopes will help "to change the way we see, the way we think, the way we do things" with regard to blind people.

\section{Vincenzo Pietropaolo}

Photographer and author

Toronto, Ont.

Mr. Pietropaolo is the author of the upcoming book, Invisible No More, a photographic chronicle of people with intellectual disabilities (Rutgers, Spring 2010).

\section{South Africa's womb}

'T his is not a place anybody would want to have a baby," says the maternity unit director as he welcomed medical students to the ward. "We have no money to replace the beds. Things are falling apart. This place was not built to respect anyone. It was built with little regard for human decency or privacy. It was built to deliver."

Chris Hani Baragwanath Hospital, or
Bara, in Soweto, South Africa, sprawls over an area the size of a small town; reportedly it is the biggest hospital in the world. The maternity unit was designed with the understanding that only Black and Coloured people* would be born here. It's more than a decade after apartheid ended, but little has changed in the 50 years since Bara was built.

A hundred pregnant women are seen in the maternity unit every day.
On arrival, the women trade their clothes for thick cotton bags tied with a drawstring above their breasts. Women on the verge of delivery are transferred to the labour ward: an echoing hall lined with 30 cubicles where about 45 vaginal deliveries and

*These are the terms of apartheid race laws, which classified the population into White, Coloured, Indian, Asian and Bantu (or Black) groups. 